\title{
Habitat complexity: approaches and future directions
}

\author{
Katya E. Kovalenko • Sidinei M. Thomaz • \\ Danielle M. Warfe
}

Received: 9 September 2011/Accepted: 27 November 2011/Published online: 21 December 2011

(C) Springer Science+Business Media B.V. 2011

\begin{abstract}
Habitat complexity is one of the most important factors structuring biotic assemblages, yet we still lack basic understanding of the underlying mechanisms. Although it is one of the primary targets in conservation management, no methods are available for comparing complexity across ecosystems, and system-specific qualitative assessment predominates. Despite its overwhelming importance for faunal diversity and abundance, there has been surprisingly little interest in examining its effects on other community and ecosystem attributes. We discuss possibilities of such effects, outlining potentially fruitful areas for future research, and argue that complexity may be implicated in community persistence and ecosystem stability by acting as a decoupling mechanism in predator-prey interactions. We provide a brief overview of methods used to quantify
\end{abstract}

Guest editors: K. E. Kovalenko \& S. M. Thomaz / The importance of habitat complexity in waterscapes

K. E. Kovalenko ( $\square)$

Department of Biological Sciences, University of Windsor, Windsor, ON N9B 3P4, Canada e-mail: katya@uwindsor.ca

\section{S. M. Thomaz}

Universidade Estadual de Maringá, DBI/Nupélia/PEA, Maringá, PR 87020-900, Brazil

D. M. Warfe

Research Institute for the Environment and Livelihoods, Charles Darwin University, Darwin, NT 0909, Australia complexity in different ecosystems, highlighting contributions of the current issue of Hydrobiologia, and discuss potential application of these approaches for cross-ecosystem comparisons. Better understanding of the role of habitat complexity resulting from such comparisons is critically important for preservation of biodiversity and ecosystem function in an era of unprecedented habitat loss.

Keywords Structural complexity · Habitat heterogeneity · Community stability · Predator-prey · Coral reefs $\cdot$ Rocky intertidal $\cdot$ Macrophytes

\section{Introduction}

Habitat complexity is one of the most intuitive concepts in ecology because humans, having been both predators and prey, subconsciously select habitats based on split-second decisions about distance-torefuge, visual obstruction, and, down-weighted accordingly, forage availability. Nevertheless, as we show in the present review, this instinctive understanding of habitat complexity has yet to bear fruit of hypothesis-driven quantitative assessment of its role in mediating and regulating major biotic processes.

One reason for this is that the importance of habitat complexity is often presented "after the fact" to explain findings where greater refuge space or greater food resources are invoked as mechanisms. Such explanations make it difficult to form generalizations regarding the 
role of habitat complexity in influencing species distributions (McCoy \& Bell, 1991; Sanson et al., 1995). A second reason is that habitat complexity is often defined using a range of terms such as "substrate heterogeneity" (Menge et al., 1985), "topographical complexity" (Walters \& Wethey, 1996), "habitat architecture" (Lawton, 1986), and is often used interchangeably with habitat heterogeneity, which should instead be defined as the diversity of structural elements (Stoner \& Lewis, 1985; Taniguchi et al., 2003). Confusion in the terms used to define habitat complexity, the measures used to quantify it, and the scales at which it is quantified has limited our understanding of its role in influencing species distributions and trophic interactions (Downes et al., 1998; Beck, 2000; Taniguchi et al., 2003; Warfe et al., 2008). In the latest review, Tokeshi \& Arakaki (2011, this issue) provide an insightful re-examination of the multi-faceted nature of habitat complexity, which includes spatial scale, diversity, size, density and arrangement of structural elements. By explicitly identifying the components of habitat complexity, such an approach should provide fertile ground for quantifying habitat complexity in a more consistent way and drawing comparisons between different habitats and ecosystems, as well as isolating the facets which may be more (or less) influential in structuring assemblages and affecting ecological processes.

This Special Issue of Hydrobiologia was designed to facilitate a cross-ecosystem exchange of ideas on how to approach the quantification of habitat complexity and discuss its effects on different levels of organization of aquatic communities and different types of habitats (Fig. 1), while paying homage to the semi-centennial of "On Bird Species Diversity" (MacArthur \& MacArthur, 1961). In this feature, we first provide a brief overview of the effect of habitat complexity on biodiversity, then discuss evidence for the role of complexity in regulating other aspects of biotic structure, outlining promising areas for future research. Finally, we review methods commonly used to quantify complexity in different ecosystems, highlighting contributions to the current issue, and discuss their potential to be used as crossecosystem measures for a more holistic understanding of the effects of habitat complexity.
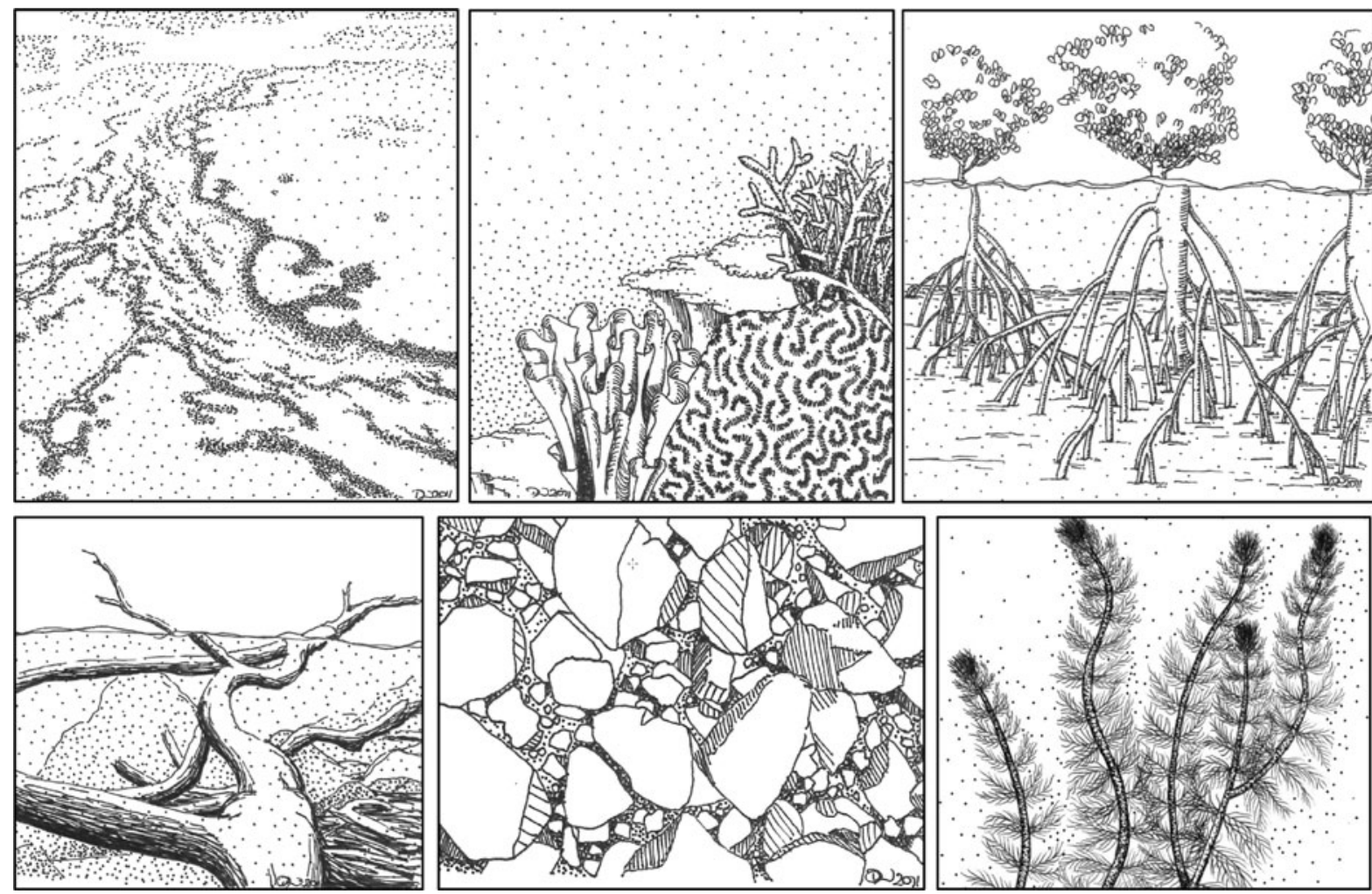

Fig. 1 Examples of complex habitats, clockwise from top left: Coral reef, corals, mangroves, woody debris, river bed, and macrophytes. Artwork by D. M. Warfe 


\section{Effects of habitat complexity on faunal diversity and abundance}

Although it is impossible to pinpoint the source of first observational evidence of complexity begetting diversity, first quantitative analysis of the effects of habitat complexity on species diversity was performed by MacArthur \& MacArthur (1961). Since then, it has persisted as a common theme in ecology, the repercussions of which in aquatic sciences are discussed by Cunha et al. (2011, this issue). Many studies have assessed local effects of habitat complexity, reporting increased richness and abundance in more complex habitats (e.g., Luckhurst \& Luckhurst, 1978; Menge et al., 1985; Dean \& Connell, 1987; Bell et al., 1991; Heck \& Crowder, 1991; Jeffries, 1993; Gee \& Warwick, 1994; Crowder et al., 1998; Kelaher \& Castilla, 2005; Matias et al., 2010). However, mechanisms behind this effect are not entirely clear, with explanations including a greater number of niches due to increased microhabitat availability, as well as higher productivity and sampling effect associated with greater surface area. In support of the greater niche space hypothesis, a study of the morphological diversity of fish assemblages concluded that both assemblage niche space and individual species niche compression increase in more complex habitats (Willis et al., 2005). The competing hypothesis asserts that complex habitats support a greater surface area, and that the greater diversity of animals found in more complex plants is actually a function of the speciesarea relationship (Heck \& Wetstone, 1977). However, it has been demonstrated that structures with more complex morphologies do not necessarily have greater surface areas (Sher-Kaul et al., 1995; Warfe et al., 2008). A number of studies have manipulated habitat complexity while holding surface area constant, or have used rarefied species richness, and have found that species respond to habitat structure independently of surface area (Warfe et al., 2008). This pattern has been shown for benthic invertebrates on rock and wood substrates in streams (O'Connor, 1991; Douglas \& Lake, 1994) and intertidal rocky shores (Beck, 2000), as well as on natural and artificial macrophytes (Jeffries, 1993; Taniguchi et al., 2003). Kolasa et al. (2011, this issue) provide further support by demonstrating that complexity resulting from spatial and temporal heterogeneity in physical parameters is a major factor explaining variability in the species-area relationship, which suggests independent effects of area and habitat complexity on species accumulation. At the patch scale, habitat complexity can increase species richness over and above effects of patch size (Taniguchi et al., 2003; Matias et al., 2010), illustrating the importance of the physical habitat per se in a range of systems and at multiple spatial scales, and its independent effects from surface, habitat, or patch area.

The positive effect of complexity on richness and abundance is likely to level off with increasing density of small uniform structures (also see Tokeshi \& Arakaki, 2011), as the habitat becomes "homogeneously diverse" (sensu Hutchinson, 1961). This highlights the importance of assessing more attributes of complexity than presence-absence or density of structures, since their arrangement, variability and the scale of perception by the organisms of interest play a critical role in mediating the effect of structural habitats.

The relationship between habitat complexity and species richness may be universal, as suggested by the role of complexity in determining richness of assemblages throughout the Phanerozoic, with the greatest richness associated with habitat-forming crinoids, bryozoans, and corals (Bambach, 1977; Kiessling et al., 2010). Mechanistic support for these paleoecological studies was offered by an observation that habitat complexity was associated with increased evolutionary diversification in bacteria by promoting genetic polymorphisms (Korona et al., 1994). In addition, a recent study showed that coral reefassociated complexity resulted in increased rates of evolution of both trophic novelty and morphological diversity (Price et al., 2011), contributing to a view of complexity as major factor not only in supporting but also in generating biodiversity.

\section{Role in conservation}

Major impacts on biodiversity highlighted in many marine and freshwater studies serve as a rationale for use of the habitat complexity concept in conservation, including the selection of protected areas and habitat enhancement using artificial reefs and other structures (e.g., Bohnsack, 1991; Hunter \& Sayer, 2009, Santos et al., 2011). The critical role of habitat complexity is also the reason for growing concern over destruction of complex habitats as a result of fishing activities 
(Alvarez-Filip et al., 2009; Buhl-Mortensen et al., 2010), as well as over the ocean-wide reduction in habitat-forming organisms due to climate change (Loya et al., 2001; Hoegh-Guldberg \& Bruno, 2010). When habitat destruction has been reversed, the increasing structural complexity of recovering biogenic reefs was tied to an increase in biodiversity (Cranfield et al., 2004). By being an important factor in determining species richness and rates of recovery, habitat complexity has a crucial influence on the relative performance of protected areas. Miller et al. (2011, this issue) show that microhabitat availability (environmental heterogeneity) should be incorporated into future assessments of the effectiveness of marine protected areas, and describe a potential framework, in which fish densities are adjusted for microhabitat availability, to accomplish this task.

Similarly popular in freshwater conservation, habitat complexity is used in such measures as the restoration of aquatic macrophytes and the addition of woody debris and rocky habitats for fish spawning and feeding (e.g., Smart \& Dick, 1999; Manny et al., 2010). The most common restoration measures in streams are habitat enhancements and channel reconfiguration, designed to increase habitat heterogeneity (Palmer et al., 2010). Recently, the potential for using artificial structures made with ceramic, concrete, and PVC to increase fish abundance and diversity was demonstrated in sub-tropical reservoirs (Santos et al., 2011). Similarly, Gois et al. (2011, this issue) conclude that keeping the arboreal vegetation in new reservoirs would help in the conservation of the fisheries resources.

The aforementioned accessibility of this concept to the general public makes it an attractive management goal; however, lack of understanding of the underlying mechanisms and of the appropriate temporal and spatial scales may result in inconsistent effects or even counter-effective measures. A recent meta-analysis demonstrates that, contrary to the common assumption that restoring habitat heterogeneity increases biodiversity, improving habitat heterogeneity in streams has not resulted in a significant increase in macroinvertebrate diversity in the vast majority of the studies (Palmer et al., 2010). This disconnect between theory and practice calls for a more mechanistic understanding of the underlying processes behind the effects of habitat complexity on biodiversity and abundance.

\section{Effects of habitat complexity on other aspects of biotic structure and ecosystem processes}

Unlike the well-documented effects of habitat complexity on biodiversity, its relationships with other aspects of biological organization remain poorly studied. For example, even though effects of habitat complexity on predator-prey interactions attract almost as much attention as its effects on richness (e.g., Crowder \& Cooper, 1982; Finke \& Denno, 2002; Warfe \& Barmuta, 2004; Grabowski et al., 2008), their implications for the general food web theory are still largely unexplored. Theoretical and early experimental studies showed that the persistence of predatorprey systems was influenced by habitat complexity (Huffaker, 1958; Cuddington \& Yodzis, 2002), but so far these ideas have been subjected to limited experimental testing. Individual-based simulations demonstrate that lower connectivity in complex, fractal environments results in decreased interaction rates and reduced functional responses, due to anomalously slow rates of movement (Cuddington \& Yodzis, 2002). Therefore, habitat complexity may be a spatial equivalent of temporal uncoupling, allowing greater predator-prey persistence than that predicted by simple models. For example, the presence of refugia decreases the likelihood of over-exploitation of prey resources (Scheffer \& De Boer, 1995; Scheffer, 1997), which would decrease population oscillations. Habitat complexity can increase community stability and persistence by reducing the potential for population "outbreaks" (Floater, 2001). Complexity can also desynchronize resources, leading to attenuated consumer fluctuations, and allow mobile predators to take advantage of variable resource availability, thus increasing stability of the overall food web (McCann \& Rooney, 2009; see also Warfe \& Barmuta, 2006).

On a larger scale, the presence of spatial structure in ecosystems has been shown to decrease the likelihood of catastrophic shifts between alternative stable states (e.g., clear vegetated vs. turbid states in shallow lakes; van Nes \& Scheffer, 2005). Since predator-prey interactions are one of the key factors in the maintenance of the clear water state (Genkai-Kato, 2007), habitat complexity should be given a central role in the alternative stable states theory, yet it has scarcely been incorporated into investigations employing this approach. Complexity at the scale of whole systems, such as characteristics of lake morphometry, can affect 
ecosystem coupling: Dolson et al. (2009) showed that lakes with a convoluted and reticulate shape interfered with the ability of fish predators to derive energy from littoral habitats, whereas in more simple circular lakes, fish were able to access relatively more littoral production and thereby couple the pelagic and littoral food webs.

Further insight into the role of habitat complexity could arise from metapopulation theory. For example, spatially explicit models with a fractal arrangement of patches show that populations on fractal landscapes can tolerate more habitat destruction than is predicted using spatially implicit models, which assume that all patches interact equally (Hill \& Caswell, 1999). These studies indicate that concerted effort to develop predictive models of the effects of habitat complexity on predator-prey population dynamics could have important repercussions for the general understanding of community structure and ecosystem stability.

Another important aspect of community structure, the degree of compartmentalization, could be highly correlated with the amount and type of habitat complexity (in particular, the range of interstitial space sizes). Structural complexity reinforces compartmentalized structure by decreasing interactions among the subgroups, e.g. larger, omnivorous predators can no longer access all habitat patches, thus giving competitive advantage to smaller intermediate predators. In turn, compartmentalization increases a system's resistance to the spread of perturbation (Kolasa, 2005) and is closely tied to long-term community persistence (Stouffer \& Bascompte, 2011). A greater range of habitat sizes allows co-existence of organisms with a wider range of body sizes, potentially leading to an increase in the number of pathways for resource utilization. An increased number of pathways, in turn, enhances resource retention and improves ecosystem resilience to perturbation (Brookes et al., 2005). Similarly, food web network attributes (e.g., connectedness and hub density) will be influenced by certain habitat characteristics such as predator-free space. More complex habitats, with size refugia excluding larger predators and decreasing intra-guild predation through spatial segregation of different cohorts, could yield lower overall connectedness. Critically important, this weakly connected trophic network architecture has been shown to increase food web stability (Thébault \& Fontaine, 2010). It is presently unclear whether these phenomena represent several distinct mechanisms, all potentially leading to greater resilience and stability of complex habitats. However, for the most part, these exciting possibilities remain untested (Fig. 2).

Little information exists to judge whether other aspects of food web structure, such as the relative representation of trophic guilds, would be similarly affected by habitat complexity across different systems. Higher habitat complexity associated with invasive freshwater bivalves leads to an increase in abundance of collectors and scrapers as well as predators

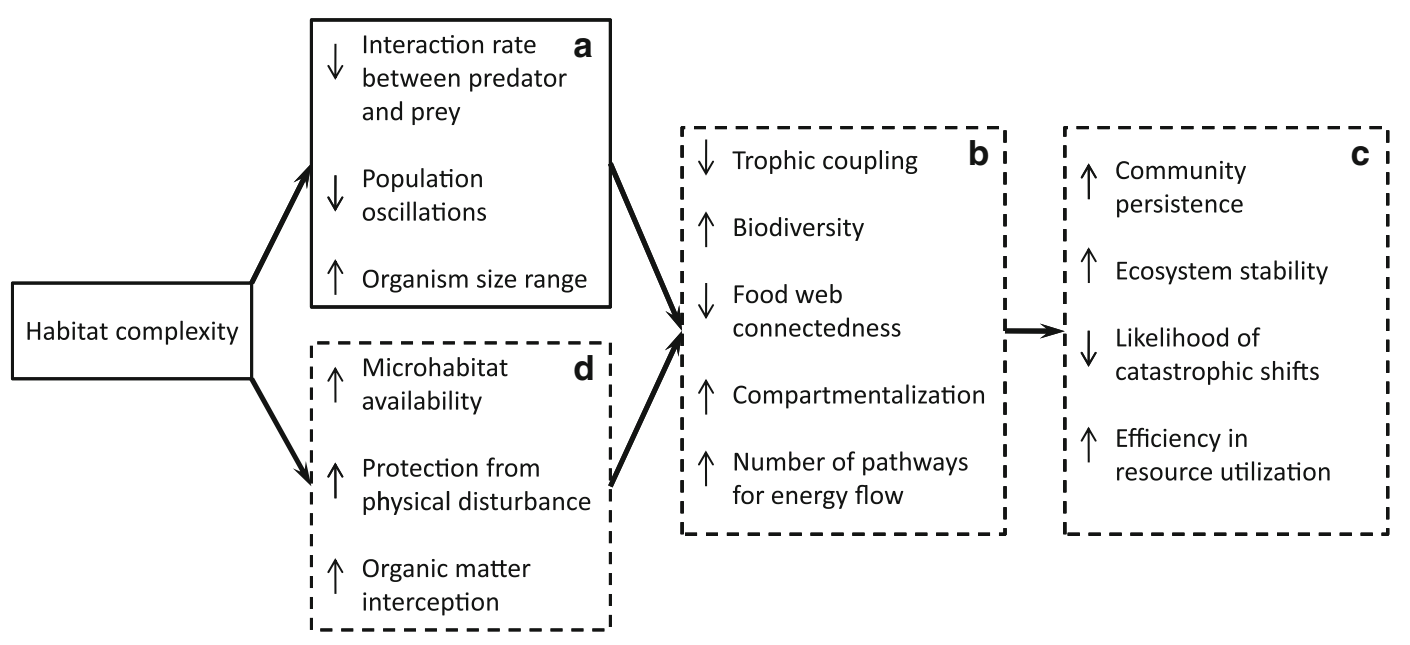

Fig. 2 Whereas effects of habitat complexity on populationlevel attributes $(a)$ are well-documented, little is known about the ensuing effects on community and ecosystem attributes $(b$, with exception of biodiversity), their emergent properties (c), and potential underlying mechanisms $(d)$ 
(Burlakova et al., 2011, this issue). Similarly, a metaanalysis of terrestrial studies found consistent increases in predator abundance in complex habitats (Langellotto \& Denno, 2004). Buhl-Mortensen et al. (2011, this issue) describe changes in feeding modes of marine benthic organisms as a function of habitat complexity on multiple scales, with one of the most apparent patterns being an increase in the proportion of suspension feeders in more complex habitats. Although availability of different food resources have been shown to vary with respect to habitat structure, e.g., chlorophyll $a$ decreasing and organic matter increasing in more complex habitats (Taniguchi \& Tokeshi, 2004), it remains to be seen whether changes in trophic guild structure could be predicted from factors such as differential food deposition due to hydrodynamic effects of habitat complexity.

Areas of high habitat complexity can play a critical role in nutrient processing within an ecosystem due to the rescaling of turbulence (reviewed in Commito \& Rusignuolo (2000) for mussels; Madsen et al. (2001) for aquatic plants), decreased flow rates (Atilla et al., 2005), and/or a greater area of reactive surfaces and higher abundance of organisms, which in combination lead to higher rates of sedimentation and retention of nutrients. For example, coral reefs have been shown to be hot spots for carbon cycling due to the interception of organic matter from the surrounding water (van Oevelen et al., 2009). In freshwater systems, higher secondary production is observed in zones of greater complexity such as littoral macrophytes and snag habitats (e.g., Benke et al., 1984). Cardinale et al. (2002) manipulated the range of sediments sizes in patches of stream, increasing substrate heterogeneity, and found corresponding increases in near-bed velocity and turbulence which led to increased rates of benthic metabolism and primary productivity. Nevertheless, despite this tantalizing evidence, there has been surprisingly little interest in a more systematic analysis of the effects of habitat complexity on nutrient cycling and carbon flows, and in its application for conservation and restoration of aquatic habitats.

It could be argued that our understanding of the role of habitat complexity has been hindered partly by the lack of repeatable quantitative methods and partly by the belief that complexity is merely a proxy for other, more primary limiting factors such as food availability. The latter would be correct in the simple case scenario, when effects of habitat complexity on community dynamics and ecosystem processes would be mediated through increased surface area for colonization and increased productivity. However, as discussed earlier, there is strong evidence that surface area is not solely responsible for the observed patterns (Douglas \& Lake, 1994; Taniguchi et al., 2003; Warfe et al., 2008); thus, the role of habitat complexity is irreducible to such simplistic interpretation. Furthermore, a continental-scale analysis of avian richness patterns demonstrated that both habitat complexity and available energy were important predictors of richness (Hurlbert, 2004), showing that this relationship applies across ecosystems. We argue that effects of habitat complexity may be mediated in a hierarchical (non-additive) way through size-specific attenuation of predator-prey interactions. Based on the evidence presented above, we suggest that habitat complexity, by acting as a decoupling mechanism, could lead to ecosystem-level effects such as an increased efficiency in utilizing resource pulses and providing greater resilience to communities from perturbations. Finally, to address the first issue, of methodological limitations, we present a brief overview of direct (Fig. 3) and indirect (Fig. 4) approaches to measuring habitat complexity commonly used in each of the most frequently studied systems.

\section{Methods for assessment of habitat complexity}

Corals

Coral reefs provide one of the most visually striking examples of the effect of habitat complexity on diversity and abundance of associated organisms, and it is perhaps not surprising that coral studies pioneered quantification of habitat complexity in aquatic ecosystems. One of the first quantitative assessments used fine-link chains to estimate coral surface area and related it to fish diversity (Risk, 1972). Luckhurst \& Luckhurst (1978) compared estimates of substrate rugosity, vertical relief and coral species richness as predictors of fish community composition. A multi-scale approach to describing complexity using fractal dimension was first proposed by Bradbury \& Reichelt (1983), and although fractal dimension values derived in this study were later challenged (Mark, 1984), this work contributed a new view of complexity as an emergent property of the 

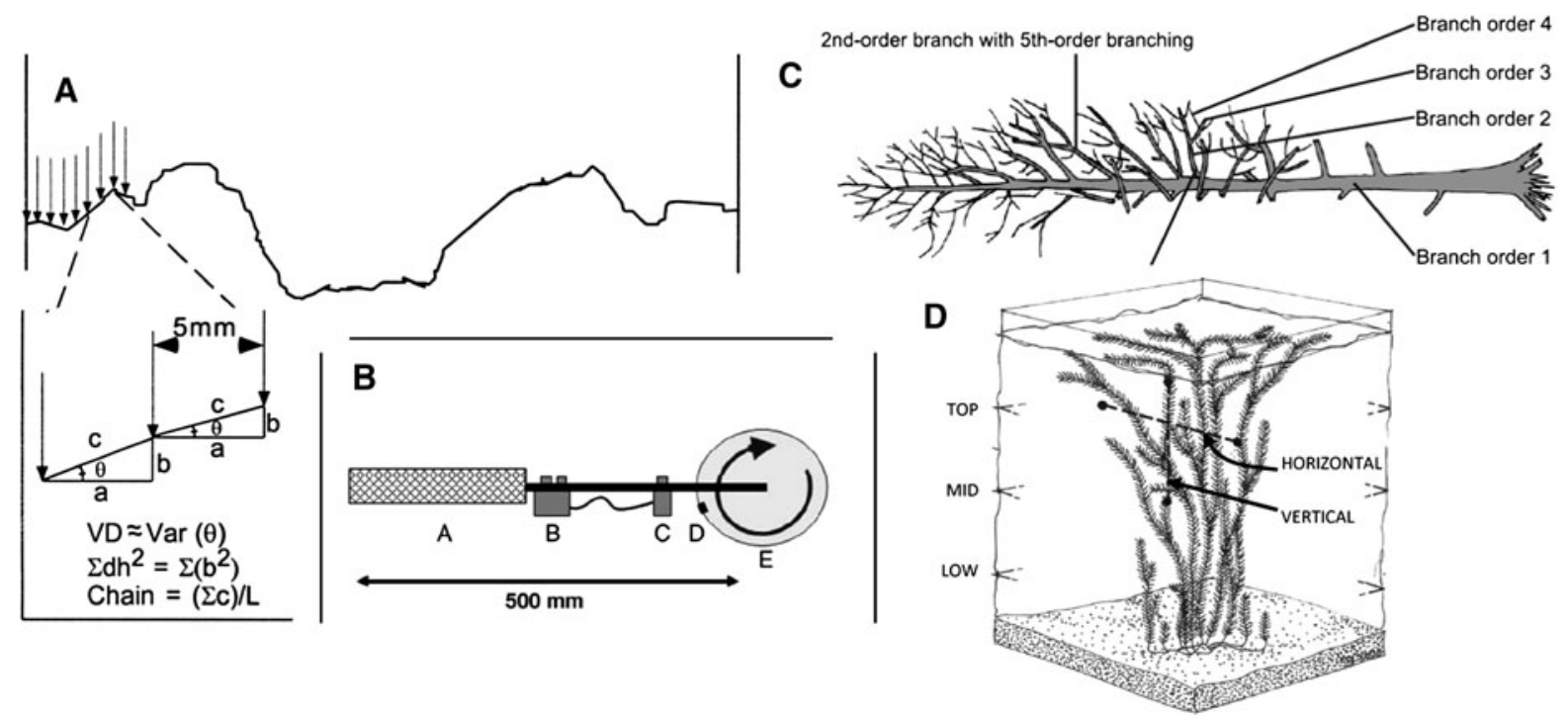

Fig. 3 Examples of direct approaches to measuring habitat complexity: A several rugosity-based measures which were applied to rocky intertidal and mangroves: vector dispersion (VD), chain-and-tape (Chain), and consecutive substratum height difference ( $\left.\sum \mathrm{d} h\right)$ (Beck, 2000); B distance-wheel for measuring relief, with interchangeable wheel and electronic

system, capable of responding to change in environmental conditions. McCormick (1994) introduced a profile gauge for measuring coral relief and compared six topographic metrics by their ability to describe the complexity of simulated substrates. Most of these metrics could differentiate among simulated profiles, with the exception of coefficient of variation of regularly measured heights (McCormick, 1994).

For small-scale analyses, both structural and textural (septal) fractal dimensions can be calculated using the Box-counting method on cross-sections of branches (Martin-Garin et al., 2007). This fractal dimension-based approach was demonstrated to be superior to linear measurements and Fourier-shape analyses, the latter being inadequate due to coral shape complexity and lack of continuous outline (MartinGarin et al., 2007). For ecological applications, it would be desirable to compare this fine-scale complexity metric to a measure of useable space, because some surfaces may be inaccessible to many macro organisms. In large-scale surveys of marine benthic structure, LiDAR (light detection and ranging) technology was demonstrated to be a useful method for measuring surface rugosity (Wedding et al., 2008; Zavada \& Brock, 2009, Fig. 4D); however, due to its large grid size, the resulting measures of habitat counter (Wilding et al., 2007, see original publication for details); C branching ratio of woody debris (Newbrey et al., 2005); and D interstitial space measurements applied to macrophytes (redrawn from Dibble et al., 1996). Reprinted from corresponding sources with kind permission from Elsevier (A, B) and NRC Research Press (C)

complexity would only be relevant for larger organisms such as fish.

Different types of corals as well as sponges and xenophyophores become increasingly important as complexity-generating organisms in deep, nutrientpoor continental margins (Buhl-Mortensen et al., 2010). Buhl-Mortensen \& Mortensen (2005) quantified the number of branches in deep-sea gorgonian corals and related it to the diversity of associated organisms. A more recent study combined highresolution multibeam surveys (bathymetry and backscatter data) with faunal assessments from video recordings and grab samples, beam trawls and epibenthic sleds to examine relationships between habitat complexity and deep-water fauna across multiple spatial scales (Buhl-Mortensen et al., 2011).

Mussel beds

Bivalves are one of the most commonly cited ecosystem engineers, their shells being an important source of structural habitat in marine, estuarine and freshwater environments. Several studies have demonstrated that greater abundance and diversity of species is associated with habitat structure provided by mussel beds (e.g., Seed, 1996; Borthagaray \& Carranza, 

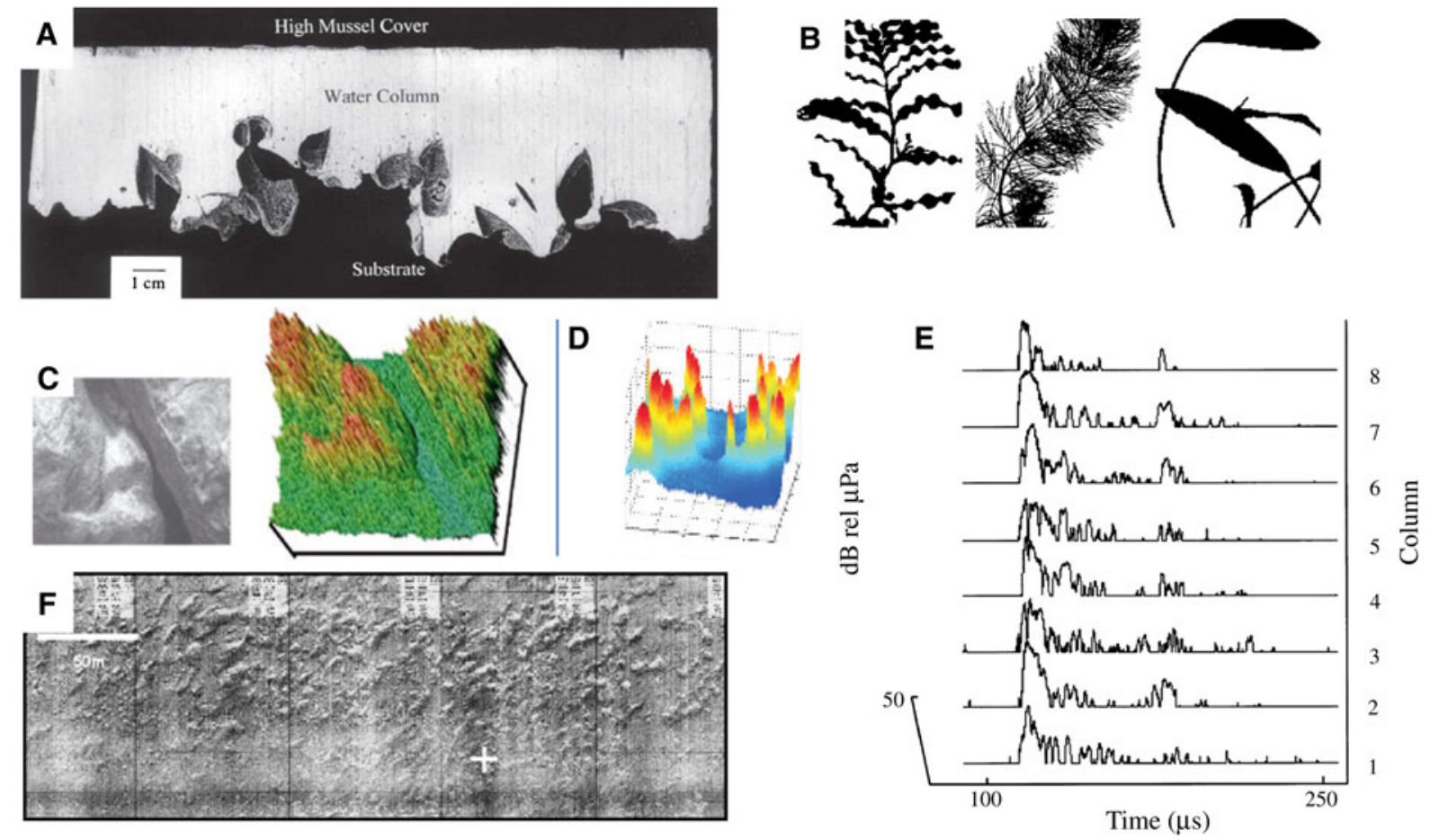

Fig. 4 Examples of indirect approaches to measuring habitat complexity: A, B photographic profiles of mussel casts (Commito \& Rusignuolo, 2000) and freshwater macrophytes (photo courtesy of E.D. Dibble and S.M. Thomaz) used for fractal dimension measurements; C optical intensity (Shumway et al., 2007); D LIDAR-derived bathymetry (Zavada \& Brock,

2007). The increased interest in studying facilitation processes in ecology in the last decade came, in part, from the recognition of the positive effect of these complexity-generating organisms on invertebrate richness (Bruno et al., 2003). The role of mussels as ecosystem engineers in their native range underlies some of the dramatic changes associated with mussel invasions. Burlakova et al. (2011) examine how changes in habitat complexity due to Limnoperna fortunei and Dreissena polymorpha invasions influence benthic macroinvertebrate communities. Their study demonstrates that greater complexity associated with mussel druses leads to increases in invertebrate richness and density, but also results in an overall homogenization of biotic communities (Burlakova et al., 2011). How the increase in local diversity coupled with larger-scale homogenization caused by invasive species would affect entire communities is still an open question of key importance for biological conservation.
2009); E high-resolution acoustics (with post-processing using chaos theory, Schwinghamer et al., 1996); F sonograms (Cranfield et al., 2004). Reprinted from corresponding sources with kind permission from Elsevier (A, F), John Wiley and Sons (C), Journal of Coastal Research (D), and NRC Research Press (E)

Although methods are available for quantitative description of mussel complexity, most studies have compared areas with and without the bivalves (reviewed in Commito \& Rusignuolo, 2000). Such designs are important to show the role of mussels and the complexity they add for other aquatic organisms, yet this binary approach does not allow for threshold determination and modeling of responses along the complexity gradient. More quantitative approaches include chain-length techniques (Aronson \& Precht, 1995) and surface area estimation from druse projection on a two-dimensional plane (Burlakova et al., 2011). Parravicini et al. (2006) developed a method for a three-dimensional estimation of surface rugosity, which was used to quantify impacts of fishing on datemussel communities. Commito \& Rusignuolo (2000) used fractal analysis of mussel plaster casts (Fig. 4A) to demonstrate that mussel-generated complexity was indeed fractal at the scales appropriate for benthic invertebrates found in this habitat. This approach 
allows assessment of the three-dimensional complexity, including overhanging and completely closed structures, which are underestimated by down-fromabove profiling techniques (Commito \& Rusignuolo, 2000). Application of this method, however, could be logistically difficult below the intertidal (e.g., for benthic mussel communities).

\section{Abiotic complexity}

Abiogenic substrates are the dominant type of complex habitat in high-energy shorelines of marine and freshwater systems as well as in fast-flowing streams, where shear stress and fluctuations in water levels prevent establishment of biogenic complexity. In addition, this type of complexity plays an important role in early stages of succession of other types of intertidal habitat, e.g., by increasing the recruitment of sessile fauna (Hills et al., 1999).

Rocky habitats have been assessed using chainand-tape techniques and fractal dimensions (Beck, 1998; Kostylev et al., 2005). The later study determined rock complexity from fractal dimensions of the vertical surface profiles measured with a contour gauge. Another approach, suggested by Wilding et al. (2007), involves the use of wheels of different sizes to measure scale-dependent habitat complexity (Fig. 3B). This approach allowed measurement over a greater range of scales than other length-of-step methods, and unlike the other step-measures, was suitable for overhangs (Wilding et al., 2007). Schwinghamer et al. (1996) applied fractal geometry to high-resolution acoustic data to describe effects of trawling on marine sediment topography (Fig. 4E). The authors suggested that decreased complexity resulting from trawling disrupts the primary ecosystem function by decreasing surface area available for materials exchange. Most recently, Tokeshi \& Arakaki (2011) developed a minimum angle-based method, capable of distinguishing between concave and convex complexity-generating elements.

In stream studies, much attention has been dedicated to size distribution of substrate particles and the resulting effects on macroinvertebrate and fish communities. Several studies assessed complexity as variability in substrate particle size (e.g., Robertson \& Milner, 2006); whereas others described substrate heterogeneity using diversity and evenness indices (Brown, 2003) and fractal dimension (Robson \&
Chester, 1999). Sanson et al. (1995) estimated surface complexity using image analysis tool with circles of different sizes on digital profiles of streambeds. A contributing review in this issue (Garcia et al., 2011) offers a hydro-morphological approach to spatial and temporal complexity of river meanders with its concomitant effects on invertebrate habitat.

Woody debris and mangrove roots

Structural habitat provided by woody debris is usually associated with greater fish (Fausch \& Northcote, 1992; Crook \& Robertson, 1999; Bond \& Lake, 2003) and invertebrate abundance (O'Connor, 1991; Entrekin et al., 2009). However, despite frequent use of woody debris additions in fishery management and stream restoration projects, few studies used quantitative indices to develop predictive models of the optimal habitat complexity. In one of the few exceptions, Newbrey et al. (2005) ingeniously applied inverted stream order classification to develop an index of branching complexity (Fig. 3C), and demonstrated that positive response of fish diversity and abundance is observed after a certain threshold value of complexity. Combining this index with information on the interstitial distances may be necessary to enable comparisons across a wider size range of woody debris. In a different approach, Kaufmann \& Faustini (2011, this issue) used dye-transit studies to demonstrate that stream channel complexity, in the form of woody debris and depth variation in thalweg profiles, led to increases in transient hydraulic storage, suggesting its potential to increase retention of nutrients and particulates.

Mangroves, with their characteristic prop roots and pneumatophores, are the coastal equivalent of freshwater flooded forests and, to a certain extent, woody debris, and have been similarly shown to play an important role in structuring fish and invertebrate assemblages (e.g., Robertson \& Duke, 1987) and providing critical nursery habitat for numerous species (reviewed in Nagelkerken et al., 2005). Although most studies compared mangrove systems with nearby areas lacking habitat structure, several attempts were made to quantify specific aspects of mangrove complexity. MacKenzie \& Cormier (2011, this issue) used ordination to summarize data on several species of mangroves of different complexity and examined potential role of mangrove complexity in posttyphoon nekton recovery. Another study used artificial 
mangrove units to disentangle effects of mangrove structure from other biotic and environmental factors (Nagelkerken et al., 2010). This latter study demonstrated that interspatial distance and the type of structure had strong effects on fish abundance and community composition, whereas length and threedimensional arrangement, modeled as a mix of hanging and standing "roots" of different length, were of lesser importance (Nagelkerken et al., 2010).

\section{Macrophytes and macroalgae}

In much of the research focusing on the role of habitat structure in aquatic systems, macrophytes have been used to represent habitat structure as they increase physical complexity in waterscapes and tend to positively affect the richness and abundance of aquatic fauna. However, similar to the situation with terrestrial vegetation (Tews et al., 2004), there are no standardized methods to measure plant complexity, which limits comparisons among plant species and ecosystems. In one of the earliest studies to investigate the distribution of invertebrates on seagrasses, Heck \& Wetstone (1977) found greater invertebrate abundance in areas of greater plant biomass, and hypothesized that this pattern was due to either (1) greater food resources, (2) greater refuge from predation, (3) greater living space, or (4) more additional habitats (i.e., habitat niches), afforded by more macrophyte biomass. After this point, study of the effect of habitat structure on species assemblages in vegetated aquatic systems began in earnest, but as in Heck \& Wetstone (1977), habitat was often only measured in terms of macrophyte biomass (e.g., Cyr \& Downing, 1988), where greater biomass was taken as a measure of greater surface area which in turn was an analogue of living space (e.g., Stoner \& Lewis, 1985; Attrill et al., 2000). Alternatively, effects of habitat structure were measured by comparing benthic macroinvertebrate communities in the presence or absence of macrophytes (e.g., Gilinsky, 1984; Diehl, 1992). More quantitative approaches have involved measuring stem density, which has also been shown to correlate with greater epifaunal diversity and abundance (e.g., Gotceitas \& Colgan, 1989; Diehl \& Kornijow, 1998; Carlisle \& Hawkins, 1998; Kornijow \& Moss, 1998).

Patterns of faunal abundance on differently shaped macrophytes are less clear, and this is a direct result of difficulties in drawing comparisons between different plant shapes. As with other systems, complexity has been inferred rather than measured, with more finely dissected forms considered more complex (Rooke, 1986; Chilton, 1990; Humphries, 1996). Structural complexity of macrophyte shape has been inferred from surface area to volume ratios (e.g., Coull \& Wells, 1983), and interstitial space to volume ratios (e.g., Hacker \& Steneck, 1990). Surface area has been determined by the surfactant technique (Harrod \& Hall, 1962) as well as traditional Euclidean approaches (McAbendroth et al., 2005), whereas volume has been measured by water displacement (e.g., Anderson et al., 2005 for kelp holdfasts). Although informative, these indices do not provide an indication of shape or the arrangement of structural elements that comprise plant shape. Other studies have attempted to address this issue by deriving indices from specific structural elements such as the number and length of leaves and/or stems per area or unit length (e.g., Stinson \& Brown, 1983), or the number and height of structural elements (e.g., Raizer \& Amaral, 2001), which again do not support straightforward comparisons between different habitats (Beck, 2000). Ranking of habitats by macrophyte cover and growth form (Höök et al., 2001), as well as by complexity of stems and root structure (Petry et al., 2003) has also been used for comparison of littoral habitats.

Another measure of macrophyte complexity considers the average size and frequency of interstitial spaces along vertical and horizontal axes, providing an indication of the degree to which interstitial space is broken by structural elements (Dibble et al., 1996, Fig. 3D). This index advanced the quantification of macrophyte complexity by enabling comparisons among different plant shapes, and marked the point at which researchers began to address the latter two Heck \& Wetstone (1977) hypotheses, relating to greater living space and more niches afforded by increased structural complexity.

Fractal geometry has also been employed to measure plant complexity in marine and freshwater ecosystems. Jeffries (1993) pioneered the use of fractal geometry to measure complexity of artificial macrophytes, and consequent studies have applied this method at a range of scales, from patches of plants in littoral zones (McAbendroth et al., 2005) to single natural macrophyte leaves (Davenport et al., 1996; Thomaz et al., 2008, Fig. 4B). Fractal dimensions of individual plants have been combined with macrophyte density and richness into a single index 
(McAbendroth et al., 2005; Kovalenko et al., 2009), streamlining comparisons of diverse macrophyte beds. These studies showed that more complex habitats had higher fractal dimensions and supported more animals; however, a study of marine macroalgae demonstrated that epifaunal abundance and biomass were related more to the scale at which complexity occurred than fractal dimension per se (Davenport et al., 1996). Although there is a range of methods for estimating macrophyte complexity, it is likely that the best and most useful estimates will involve a combination of methods which can be applied over a range of scales and which will allow comparisons between habitats and systems (Downes et al., 1998; Beck, 2000; Warfe et al., 2008).

Towards the cross-ecosystem comparison of the effects of habitat complexity

Can structural complexity provided by sunken rigs compensate for corals destroyed by decades of fishing? Two separate issues arise when trying to answer this important question: first, only some attributes of habitat complexity are assessed by most studies, whereas the importance of other attributes, such as arrangement of spatial elements, is virtually unknown (Tokeshi \& Arakaki, 2011). Second, even the simplest attribute of complexity, the density of elements, has rarely been compared among habitats (but see Beck, 1998). (It is important to note that in this particular example, other factors beyond the scope of this discussion such as toxic residues and the nature of the substratum for attachment may greatly affect colonization and community persistence.) The ability to compare effects of habitat complexity across systems is essential for comparing the relative value of different habitat types (e.g., seagrass meadows, corals, and mangroves, Nagelkerken et al., 2000), as well as for describing general ecological patterns for a more mechanistic understanding of the role of complexity. Therefore, habitat complexity studies must prioritize the development of more universal approaches, with a note of caution that no single index could be used for describing every aspect of complexity at different scales, but rather emphasizing the need for a clear description of the feature of complexity under study, and for a calibration curve which could be used to compare findings among systems.
Several of the aforementioned approaches hold promise for application across different types of marine and freshwater habitats. Fractal dimension is a commonly used measure which has been applied in many studies (e.g., Bradbury \& Reichelt, 1983; Jeffries, 1993; Beck, 2000; Commito \& Rusignuolo, 2000), however, it could be system-specific and even study-specific depending on the method used to estimate fractal dimension. Frost et al. (2005) demonstrated that although methods using chains and profile gauges gave similar estimates of fractal complexity, stereo photography generated highly disparate results. Most fractal indices were derived from one- or two-dimensional measurements (reviewed in Davenport, 2004, but see Commito \& Rusignuolo, 2000), and although three-dimensional fractal indices would certainly add realism to the assessment of habitat complexity, several additional issues remain. For example, different structures with identical fractal values may have different spatial arrangement of elements (Tokeshi \& Arakaki, 2011). In addition, an important assumption of fractal analysis about identical patterns across several scales of observation may not hold true for many natural systems.

Indices relying on linear measurements of interstitial spaces have also been used for assessing complexity in several types of substrates (Dibble et al., 1996; Buhl-Mortensen \& Mortensen, 2005). The aforementioned index of macrophyte complexity, which incorporates the frequency of interstices along horizontal and vertical axes (Dibble et al., 1996), could be compared with measures of woody debris complexity based on the degree of branching. Interstitial space can also be quantified for mussels, corals and some abiogenic substrates. In acknowledgment of the fact that interstitial space does not necessarily equate with available living space, Bartholomew et al. (2000) explicitly scaled their measurement of structural complexity to refuge availability and developed an index based on the average interstitial space size divided by the size of a predator. This index is dimensionless and specifically scaled to the organisms of interest, and also provides an effective measure for comparing across different habitats and ecosystems (Bartholomew et al., 2000; Warfe et al., 2008; but see Bell et al., 2003).

Most measures of rugosity, or unevenness of surface topography, frequently used in marine studies, were developed for hard substrates (e.g., Luckhurst \& 
Luckhurst, 1978; McCormick, 1994). Most recently, Shumway et al. (2007) proposed a novel method for estimating complexity of surface topography using optical intensity. This metric is closely correlated with rugosity, but unlike the latter, allows for the scale adjustment at a later point, could be used at different depths (Shumway et al., 2007), and has a potential for application to soft structures such as macrophytes. Alternatively, indirect measures of complexity such as decreases in flow rates or increases in turbulence could provide additional information for comparing different habitat types in the context of their functional responses.

It is important to note that, due to methodological limitations, many linear measurement-based methods can underestimate complexity because they are unable to account for overhanging structures and 'bottleneck' type crevices (Commito \& Rusignuolo, 2000). These structures may be the critical absolute refugia allowing the decoupling or weakening of predator-prey interactions that were discussed in earlier sections, and failure to account for their effect may strongly underestimate the importance of complexity. In contrast, fine-resolution measurements of interstitial space and fractal dimension can overestimate complexity by quantifying habitat features which are unuseable by most macro organisms. As a final consideration, the range of interstitial space sizes is a much more informative measure of complexity than the average space size (Warfe et al., 2008; Tokeshi \& Arakaki, 2011), and needs to be taken into consideration in future attempts to develop complexity indices.

A comprehensive comparison of nine most common macrophyte complexity indices found that they were highly correlated (Warfe et al., 2008). This degree of correspondence among indices based on different approaches indicates that there is a possibility for crossecosystem comparisons, when information about complexity is accompanied by scale-specific calibration data.

\section{Conclusion}

There is clear evidence of the role of habitat complexity for faunal diversity and abundance, although the mechanisms behind this effect are still ambiguous. In addition, there is intriguing evidence of the more general importance of habitat complexity for community structure and ecosystem processes, which thus far have received limited attention. We argue that increasing habitat complexity may decouple trophic interactions and subsequently increase ecosystem stability, and that these questions would be promising subjects to explore in future studies.

We anticipate that future studies on habitat complexity use a variety of approaches from different systems, which we have attempted to cover in this issue. Quantitative indices of habitat complexity are available for most habitat types and should be more widely employed in future studies to better understand the mechanistic role of habitat structure. Some of these indices could be developed further to enable consistent comparison among different habitats, thus alleviating the problem of the lack of integration between fields. Different approaches could be compared across studies provided they are accompanied by information on the specific attributes of complexity measured and a calibration curve.

Future studies should be designed to incorporate the existing knowledge and redefine the null hypothesis from simple binomial testing of the presence/absence of the effect of habitat complexity, to encourage a more quantitatively rigorous assessment. Continuing progress of complexity studies is contingent on approaching questions related to other aspects of biological systems, such as nutrient retention and food web structure, and not only species richness and abundance. This is particularly important because studies focusing on richness could be overlooking significant effects of habitat modification on food web structure and ecosystem functions (Tylanakis et al., 2007). We foresee this effort leading to a more robust use of the habitat complexity concept in conservation, ever more important in the face of accelerating habitat destruction and homogenization.

Acknowledgments We would like to thank all our contributors and reviewers, Koen Martens for providing us with an opportunity to have this special issue and the editorial staff of Hydrobiologia. We are grateful to Eric Dibble for insightful discussions, Michelle Dobrin and Lyndon Barr for proofreading and comments on design, and Sergey Ilyushkin, Lene Buhl-Mortensen and an anonymous reviewer for their helpful suggestions. SM Thomaz is especially thankful to the Brazilian Council of Research (CNPq) for continuous funding through a Research Productivity Grant.

\section{References}

Alvarez-Filip, L., N. K. Dulvy, J. A. Gill, I. M. Côté \& A. R. Watkinson, 2009. Flattening of Caribbean coral reefs: 
region-wide declines in architectural complexity. Proceedings of the Royal Society Biological Sciences 276: 3019-3025.

Anderson, M. J., C. E. Diebel, W. M. Blom \& T. J. Landers, 2005. Consistency and variation in kelp holdfast assemblages: spatial patterns of biodiversity for the major phyla at different taxonomic resolutions. Journal of Experimental Marine Biology and Ecology 320: 35-56.

Aronson, R. B. \& W. F. Precht, 1995. Landscape patterns of reef coral diversity: a test of the intermediate disturbance hypothesis. Journal of Experimental Marine Biology and Ecology 192: 1-14.

Atilla, N., J. W. Fleeger \& C. M. Finelli, 2005. Effects of habitat complexity and hydrodynamics on the abundance and diversity of small invertebrates colonizing artificial substrates. Journal of Marine Research 63: 1151-1172.

Attrill, M. J., J. A. Strong \& A. A. Rowden, 2000. Are macroinvertebrate communities influenced by seagrass structural complexity? Ecography 23: 114-121.

Bambach, R. K., 1977. Species richness in marine benthic habitats through the Phanerozoic. Paleobiology 3: 152-167.

Bartholomew, A., R. J. Diaz \& G. Cicchetti, 2000. New dimensionless indices of structural habitat complexity: predicted and actual effects on a predator's foraging success. Marine Ecology Progress Series 206: 45-58.

Beck, M. W., 1998. Comparison of the measurement and effects of habitat structure on gastropods in rocky intertidal and mangrove habitats. Marine Ecology Progress Series 169: $165-178$.

Beck, M. W., 2000. Separating the elements of habitat structure: independent effects of habitat complexity and structural components on rocky intertidal gastropods. Journal of Experimental Marine Biology and Ecology 249: 29-49.

Bell, S. S., E. D. McCoy \& H. R. Mushinsky, 1991. Habitat Structure: the physical arrangement of objects in space. Chapman and Hall, London.

Bell, S. S., R. A. Brooks \& W. E. Ellis, 2003. Structural spacing, the determination of habitat complexity: examining the Bartholomew et al. (2000) index. Marine Ecology Progress Series 248: 293-295.

Benke, A. C., T. C. Van Arsdall Jr., D. M. Gillespie \& F. K. Parrish, 1984. Invertebrate productivity in a subtropical blackwater river: the importance of habitat and life history. Ecological Monographs 54: 25-63.

Bohnsack, J. A., 1991. Habitat structure and the design of artificial reefs. In Bell, S. S., E. D. McCoy \& H. R. Mushinsky (eds), Habitat Structure: the physical arrangement of objects in space. Chapman and Hall, London: 412-426.

Bond, N. R. \& P. S. Lake, 2003. Characterising fish-habitat associations in streams as the first step in ecological restoration. Austral Ecology 28: 611-621.

Borthagaray, A. I. \& A. Carranza, 2007. Mussels as ecosystem engineers: their contribution to species richness in a rocky littoral community. Acta Oecologica 31: 243-250.

Bradbury, R. H. \& R. E. Reichelt, 1983. Fractal dimension of a coral reef at ecological scales. Marine Ecology Progress Series 10: 169-171.

Brookes, J. D., K. Aldridge, T. Wallace, L. Linden \& G. G. Ganf, 2005. Multiple interception pathways for resource utilisation and increased ecosystem resilience. Hydrobiologia 552: 135-146.
Brown, B. L., 2003. Spatial heterogeneity reduces temporal variability in stream insect communities. Ecology Letters 6: 316-325.

Bruno, J. F., J. J. Stachowicz \& M. D. Bertness, 2003. Inclusion of facilitation into ecological theory. Trends in Ecology \& Evolution 18: 119-125.

Buhl-Mortensen, L. \& P. B. Mortensen, 2005. Distribution and diversity of species associated with deep-sea gorgonian corals off Atlantic Canada. In Freiwald, A. \& J. M. Roberts (eds), Cold-water Corals and Ecosystems. Springer-Verlag, Berlin Heidelberg: 849-879.

Buhl-Mortensen, L., A. Vanreusel, A. J. Gooday, L. A. Levin, I. G. Priede, P. Buhl-Mortensen, H. Gheerardyn, N. J. King \& M. Raes, 2010. Biological structures as a source of habitat heterogeneity and biodiversity on the deep ocean margins. Marine Ecology 31(1): 21-50.

Buhl-Mortensen, L., P. Buhl-Mortensen, M. F. J. Dolan, J. Dannheim, V. Bellec \& B. Holte, 2011. Habitat complexity and bottom fauna composition at different scales on the continental shelf and slope of Northern Norway. Hydrobiologia. (In press).

Burlakova, L. E., A. Y. Karatayev \& V. A. Karatayev, 2011. Invasive mussels induce community changes by increasing habitat complexity. Hydrobiologia. doi:10.1007/s10750011-0791-4.

Cardinale, B. J., M. A. Palmer, C. M. Swan, S. Brooks \& N. L. Poff, 2002. The influence of substrate heterogeneity on biofilm metabolism in a stream ecosystem. Ecology 83: 412-422.

Carlisle, D. M. \& C. P. Hawkins, 1998. Relationships between invertebrate assemblage structure, two trout species, and habitat structure in Utah mountain lakes. Journal of the North American Benthological Society 17: 286-300.

Chilton, E. W. II, 1990. Macroinvertebrate communities associated with three aquatic macrophytes (Ceratophyllum demersum, Myriophyllum spicatum, and Vallisneria americana) in Lake Onalaska, Wisconsin. Journal of Freshwater Ecology 5: 455-466.

Commito, J. A. \& B. R. Rusignuolo, 2000. Structural complexity in mussel beds: the fractal geometry of surface topography. Journal of Experimental Marine Biology and Ecology 255: 133-152.

Coull, B. C. \& J. B. J. Wells, 1983. Refuges from fish predation: experiments with phytal meiofauna from the New Zealand rocky intertidal. Ecology 64: 1599-1609.

Cranfield, H. J., A. A. Rowden, D. J. Smith, D. P. Gordon \& K. P. Michael, 2004. Macrofaunal assemblages of benthic habitat of different complexity and the proposition of a model of biogenic reef habitat regeneration in Foveaux Strait, New Zealand. Journal of Sea Research 52: 109-125.

Crook, D. A. \& A. I. Robertson, 1999. Relationships between riverine fish and woody debris: implications for lowland rivers. Marine and Freshwater Research 51: 941-953.

Crowder, L. B. \& W. E. Cooper, 1982. Habitat structural complexity and the interaction between bluegills and their prey. Ecology 63: 1802-1813.

Crowder, L. B., E. W. McCollum \& T. H. Martin, 1998. Changing perspectives on food web interactions in lake littoral zones. In Jeppensen, E., M. Sondegaard, M. Sondegaard \& K. Christoffersen (eds), The Structuring 
Role of Submerged Macrophytes in Lakes. Springer, Berlin: 240-249.

Cuddington, K. \& P. Yodzis, 2002. Predator-prey dynamics and movement in fractal environments. American Naturalist 160: 119-134.

Cunha, E. R., T. S. Michelan, K. E. Kovalenko \& S. M. Thomaz, 2011. Flying over water: how "On bird species diversity" influenced aquatic ecology. Hydrobiologia. doi: 10.1007/s10750-011-0859-1.

Cyr, H. \& J. A. Downing, 1988. Empirical relationships of phytomacrofaunal abundance to plant biomass and macrophyte bed characteristics. Canadian Journal of Fisheries and Aquatic Sciences 45: 976-984.

Davenport, J., 2004. Fractal dimension estimation in studies of epiphytal and epilithic communities: strengths and weaknesses. In Strutton, P. G. \& L. Seuront (eds), Handbook of Scaling Methods in Aquatic Ecology: Measurement, Analysis, Simulation. CRC Press, New York: 245-256.

Davenport, J., P. J. A. Pugh \& J. McKechnie, 1996. Mixed fractals and anisotropy in subantarctic marine macroalgae from South Georgia: implications for epifaunal biomass and abundance. Marine Ecology Progress Series 136: 245-255.

Dean, R. L. \& J. H. Connell, 1987. Marine invertebrates in an algal succession III. Mechanisms linking habitat complexity with diversity. Journal of Experimental Marine Biology and Ecology 109: 249-273.

Dibble, E. D. \& S. M. Thomaz, 2009. Use of fractal dimension to assess habitat complexity and its influence on dominant invertebrates inhabiting tropical and temperate macrophytes. Journal of Freshwater Ecology 24: 93-102.

Dibble, E. D., K. J. Killgore \& G. O. Dick, 1996. Measurement of plant architecture in seven aquatic plants. Journal of Freshwater Ecology 11: 311-318.

Diehl, S., 1992. Fish predation and benthic community structure: the role of omnivory and habitat complexity. Ecology 73: $1646-1661$.

Diehl, S. \& R. Kornijow, 1998. Influence of submerged macrophytes on trophic interactions among fish and macroinvertebrates. In Jeppesen, E., M. Sondegaard, M. Sondegaard \& K. Christoffersen (eds), The Structuring Role of Submerged Macrophytes in Lakes. Springer-Verlag, New York: 24-46.

Dolson, R., K. McCann, N. Rooney \& M. Ridgway, 2009. Lake morphometry predicts the degree of habitat coupling by a mobile predator. Oikos 118: 1230-1238.

Douglas, M. M. \& P. S. Lake, 1994. Species richness of stream stones: an investigation of the mechanisms generating the species-area relationship. Oikos 69: 387-396.

Downes, B. J., P. S. Lake, E. S. G. Schreiber \& A. Glaister, 1998. Habitat structure and regulation of local species diversity in a stony upland stream. Ecological Monographs 68: 237-257.

Entrekin, S. A., J. L. Tank, E. J. Rosi-Marshall, T. J. Hoellein \& G. A. Lamberti, 2009. Response of secondary production by macroinvertebrates to large wood addition in three Michigan streams. Freshwater Biology 54: 1741-1758.

Fausch, K. D. \& T. G. Northcote, 1992. Large woody debris and salmonid habitat in a small coastal British Columbia stream. Canadian Journal of Fisheries and Aquatic Sciences 49: 682-693.
Finke, D. L. \& R. F. Denno, 2002. Intraguild predation diminished in complex-structure vegetation: implications for prey suppression. Ecology 83: 643-652.

Floater, G. J., 2001. Habitat complexity, spatial interference and "minimum risk distribution": a framework for population stability. Ecological Monographs 71: 447-468.

Frost, N. J., M. T. Burrows, M. P. Johnson, M. E. Hanley \& S. J. Hawkins, 2005. Measuring surface complexity in ecological studies. Limnology and Oceanography: Methods 3: 203-210.

Garcia, X.-F., I. Schnauder \& M. T. Pusch, 2011. Complex hydromorphology of meanders can support benthic invertebrate diversity in rivers. Hydrobiologia. doi:10.1007/ s10750-011-0905-z.

Gee, J. M. \& R. M. Warwick, 1994. Metazoan community structure in relation to the fractal dimensions of marine macroalgae. Marine Ecology Progress Series 103: 141-150.

Genkai-Kato, M., 2007. Macrophyte refuges, prey behaviour and trophic interactions: consequences for lake water clarity. Ecology Letters 10: 105-114.

Gilinsky, E., 1984. The role of fish predation and spatial heterogeneity in determining benthic community structure. Ecology 65: 455-468.

Gois, K. S., R. R. Antonio, L. C. Gomes, F. M. Pelicice \& A. A. Agostinho, 2011. The role of submerged trees in structuring fish assemblages in reservoirs: two case studies in South America. Hydrobiologia. doi:10.1007/s10750011-0843-9.

Gotceitas, V. \& P. Colgan, 1989. Predator foraging success and habitat complexity: quantitative test of the threshold hypothesis. Oecologia 80: 158-166.

Grabowski, J. H., A. R. Hughes \& D. L. Kimbro, 2008. Habitat complexity influences cascading effects of multiple predators. Ecology 89: 3413-3422.

Hacker, S. D. \& R. S. Steneck, 1990. Habitat architecture and the abundance and body-size dependent habitat selection of a phytal amphipod. Ecology 71: 2269-2285.

Harrod, J. J. \& R. E. Hall, 1962. Method for determining the surface areas of various aquatic plants. Hydrobiologia 20: 173-178.

Heck, K. L. J. \& L. B. Crowder, 1991. Habitat structure and predator-prey interactions in vegetated aquatic systems. In Bell, S. S., E. D. McCoy \& H. R. Mushinsky (eds), Habitat structure: the physical arrangement of objects in space. Chapman and Hall, London: 281-299.

Heck, K. L. J. \& G. S. Wetstone, 1977. Habitat complexity and invertebrate species richness and abundance in tropical seagrass meadows. Journal of Biogeography 4: 135-142.

Hill, M. F. \& H. Caswell, 1999. Habitat fragmentation and extinction thresholds on fractal landscapes. Ecology Letters 2: 121-127.

Hills, J. M., J. C. Thomason \& J. Muhl, 1999. Settlement of barnacle larvae is governed by Euclidean and not fractal surface characteristics. Functional Ecology 13: 868-875.

Hoegh-Guldberg, O. \& J. F. Bruno, 2010. The impact of climate change on the world's marine ecosystems. Science 328: 1523-1528.

Höök, T. O., N. M. Eagan \& P. W. Webb, 2001. Habitat and human influences on larval fish assemblages in northern Lake Huron coastal marsh bays. Wetlands 21: 281-291. 
Huffaker, C. B., 1958. Experimental studies on predation: dispersion factors and predator-prey oscillations. Hilgardia 27: 795-835.

Humphries, P., 1996. Aquatic macrophytes, macroinvertebrates associations and water levels in a lowland Tasmanian river. Hydrobiologia 321: 219-233.

Hunter, W. R. \& M. D. J. Sayer, 2009. The comparative effects of habitat complexity on faunal assemblages of northern temperate artificial and natural reefs. ICES Journal of Marine Science 66: 691-698.

Hurlbert, A. H., 2004. Species-energy relationships and habitat complexity in bird communities. Ecology Letters 7: 714-720.

Hutchinson, G. E., 1961. The paradox of the plankton. American Naturalist 95: 137-145.

Jeffries, M., 1993. Invertebrate colonization of artificial pondweeds of differing fractal dimension. Oikos 67: 142-148.

Kaufmann, P. R. \& J. M. Faustini, 2011. Simple measures of channel habitat complexity predict transient hydraulic storage in streams. Hydrobiologia. doi:10.1007/s 10750-011-0841-y.

Kelaher, B. P. \& J. C. Castilla, 2005. Habitat characteristics influence macrofaunal communities in coralline turf more than mesoscale upwelling on the coast of Northern Chile. Estuarine, Coastal and Shelf Science 63: 155-165.

Kiessling, W., C. Simpson \& M. Foote, 2010. Reefs as cradles of evolution and sources of biodiversity in the Phanerozoic. Science 327: 196-198.

Kolasa, J., 2005. Complexity, system integration, and susceptibility to change: biodiversity connection. Ecological Complexity 2: 431-442.

Kolasa, J., L. L. Manne \& S. N. Pandit. 2011. Species-area relationships arise from interaction of habitat heterogeneity and species pool. Hydrobiologia. doi:10.1007/s10750011-0846-6.

Kornijow, R. \& B. Moss, 1998. Vertical distribution of inbenthos in relation to fish and floating-leaved macrophyte populations. In Jeppesen, E., M. Sondegaard, M. Sondegaard \& K. Christoffersen (eds), The Structuring Role of Submerged Macrophytes in Lakes. Springer-Verlag, New York: 227-232.

Korona, R., C. H. Nakatsu, L. J. Forney \& R. E. Lenski, 1994. Evidence for multiple adaptive peaks from populations of bacteria evolving in a structured habitat. Proceedings of the National Academy of Sciences 91: 9037-9041.

Kostylev, V. E., J. Erlandsson, M. Y. Ming \& G. A. Williams, 2005. The relative importance of habitat complexity and surface area in assessing biodiversity: fractal application on rocky shores. Ecological Complexity 2: 272-286.

Kovalenko, K., E. D. Dibble \& R. Fugi, 2009. Fish feeding in changing habitats: effects of invasive macrophyte control and habitat complexity. Ecology of Freshwater Fish 18: 305-313.

Langellotto, G. A. \& R. F. Denno, 2004. Responses of invertebrate natural enemies to complex-structured habitats: a meta-analytical synthesis. Oecologia 139: 1-10.

Lawton, J. H., 1986. Surface availability and insect community structure: the effects of architecture and the fractal dimension of plants. In Juniper, B. E. \& T. R. E. Southwood (eds), Insects and the Plant Surface. Edward Arnold, London: 317-331.
Loya, Y., K. Sakai, K. Yamazato, Y. Nakano, H. Sambali \& R. Van Woesik, 2001. Coral bleaching: the winners and the losers. Ecology Letters 4: 122-131.

Luckhurst, B. E. \& K. Luckhurst, 1978. Analysis of the influence of substrate variables on coral reef fish communities. Marine Biology 49: 317-323.

MacArthur, R. H. \& J. W. MacArthur, 1961. On bird species diversity. Ecology 42: 594-598.

MacKenzie, R. A. \& N. Cormier, 2011. Stand structure influences nekton community composition and provides protection from natural disturbance in Micronesian mangroves. Hydrobiologia. doi:10.1007/s10750-0110865-3.

Madsen, J. D., P. A. Chambers, W. F. James, E. W. Koch \& D. F. Westlake, 2001. The interaction between water movement, sediment dynamics and submersed macrophytes. Hydrobiologia 444: 71-84.

Manny, B. A., G. W. Kennedy, J. C. Boase, J. D. Allen \& E. F. Roseman, 2010. Spawning by walleye (Sander vitreus) and white sucker (Catostomus commersoni) in the Detroit River: implications for spawning habitat enhancement. Journal of Great Lakes Research 36: 490-496.

Mark, D. M., 1984. Fractal dimension of a coral reef at ecological scales: a discussion. Marine Ecology Progress Series 14: 293-294.

Martin-Garin, B., B. Lathuilière, E. P. Verrecchia \& J. Geister, 2007. Use of fractal dimensions to quantify coral shape. Coral Reefs 26: 541-550.

Matias, M. G., A. J. Underwood, D. F. Hochuli \& R. A. Coleman, 2010. Independent effects of patch size and structural complexity on diversity of benthic invertebrates. Ecology 91: 1908-1915.

McAbendroth, L., P. M. Ramsay, A. Foggo, S. D. Rundle \& D. T. Bilton, 2005. Does macrophytes fractal complexity drive invertebrate diversity, biomass and body size distributions? Oikos 111: 279-290.

McCann, K. S. \& N. Rooney, 2009. The more food webs change, the more they stay the same. Philosophical Transactions of the Royal Society B 364: 1789-1801.

McCormick, M., 1994. Comparison of field methods for measuring surface topography and their associations with a tropical reef fish assemblage. Marine Ecology Progress Series 112: 87-96.

McCoy, E. D. \& S. S. Bell, 1991. Habitat structure: the evolution and diversification of a complex topic. In Bell, S. S., E. D. McCoy \& H. R. Mushinsky (eds), Habitat Structure: the physical arrangement of objects in space. Chapman and Hall, London: 3-27.

Menge, B. A., J. Lubchenko \& L. R. Ashkenas, 1985. Diversity, heterogeneity and consumer pressure in a tropical rocky intertidal community. Oecologia 65: 394-405.

Miller, S. L., J. S. Shima \& N. E. Phillips, 2011. Effects of microhabitat availability on estimates of density of a reef fish: implications for assessments of marine protected areas. Hydrobiologia. doi:10.1007/s10750-011-0911-1.

Nagelkerken, I., G. van der Velde, M. W. Gorissen, G. J. Meijer, T. van't Hof \& C. den Hartoga, 2000. Importance of mangroves, seagrass beds and the shallow coral reef as a nursery for important coral reef fishes, using a visual census technique. Estuarine, Coastal and Shelf Science 51: 31-44. 
Nagelkerken, I., S. J. M. Blaber, S. Bouillon, P. Green, M. Haywood, L. G. Kirton, J.-O. Meynecke, J. Pawlik, H. M. Penrose, A. Sasekumar \& P. J. Somerfield, 2005. The habitat function of mangroves for terrestrial and marine fauna: a review. Aquatic Botany 89: 155-185.

Nagelkerken, I., A. M. De Schryver, M. C. Verweij, F. Dahdouh-Guebas, G. van der Velde \& N. Koedam, 2010. Differences in root architecture influence attraction of fishes to mangroves: a field experiment mimicking roots of different length, orientation, and complexity. Journal of Experimental Marine Biology and Ecology 396: 27-34.

Newbrey, M. G., M. A. Bozek, M. J. Jennings \& J. E. Cook, 2005. Branching complexity and morphological characteristics of coarse woody structure as lacustrine fish habitat. Canadian Journal of Fisheries and Aquatic Sciences 62: 2110-2123.

O'Connor, N. A., 1991. The effects of habitat complexity on the macroinvertebrate colonizing wood substrates in lowland stream. Oecologia 85: 504-512.

Palmer, M. A., H. L. Menninger \& E. Bernhardt, 2010. River restoration, habitat heterogeneity and biodiversity: a failure of theory or practice? Freshwater Biology 55(Suppl. 1): 205-222.

Parravicini, V., A. Rovere, M. Donato, C. Morri \& C. N. Bianchi, 2006. A method to measure three-dimensional substratum rugosity for ecological studies: an example from the date-mussel fishery desertification in the north-western Mediterranean. Journal of the Marine Biological Association (UK) 86: 689-690.

Petry, P., P. B. Bayley \& D. F. Markle, 2003. Relationships between fish assemblages, macrophytes and environmental gradients in the Amazon River floodplain. Journal of Fish Biology 63: 547-579.

Price, S. A., R. Holzman, T. J. Near \& P. C. Wainwright, 2011. Coral reefs promote the evolution of morphological diversity and ecological novelty in labrid fishes. Ecology Letters 14: 462-469.

Raizer, J. \& M. E. C. Amaral, 2001. Does the structural complexity of aquatic macrophytes explain the diversity of associated spider assemblages? Journal of Arachnology 29: 227-237.

Risk, M. J., 1972. Fish diversity on a coral reef in the Virgin Islands. Atoll Research Bulletin 153: 1-6.

Robertson, A. \& N. Duke, 1987. Mangroves as nursery sites: comparisons of the abundance and species composition of fish and crustaceans in mangroves and other nearshore habitats in tropical Australia. Marine Biology 96: 193-205.

Robertson, A. L. \& A. M. Milner, 2006. The influence of stream age and environmental variables in structuring meiofaunal assemblages in recently deglaciated streams. Limnology and Oceanography 51: 1454-1465.

Robson, B. J. \& E. T. Chester, 1999. Spatial patterns of invertebrate species richness in a river: the relationship between riffles and microhabitats. Australian Journal of Ecology 24: 599-607.

Rooke, B., 1986. Macroinvertebrates associated with macrophytes and plastic imitations in the Eramosa River, Ontario, Canada. Archiv für Hydrobiologie 106: 307-325.

Sanson, G. D., R. Stolk \& B. J. Downes, 1995. A new method for characterizing surface roughness and available space in biological systems. Functional Ecology 9: 127-135.
Santos, L. N., E. Garcia-Berthou, A. A. Agostinho \& J. D. Latini, 2011. Fish colonization of artificial reefs in a large Neotropical reservoir: material type and successional changes. Ecological Applications 21: 251-262.

Scheffer, M., 1997. On the implications of predator avoidance. Aquatic Ecology 31: 99-107.

Scheffer, M. \& R. J. De Boer, 1995. Implications of spatial heterogeneity for the paradox of enrichment. Ecology 76: 2270-2277.

Schwinghamer, P., J. Y. Guigné \& W. C. Siu, 1996. Quantifying the impact of trawling on benthic habitat structure using high resolution acoustics and chaos theory. Canadian Journal of Fisheries and Aquatic Sciences 53: 288-296.

Seed, R., 1996. Patterns of biodiversity in the macro-invertebrate fauna associated with mussel patches on rocky shores. Journal of the Marine Biological Association (UK) 76: 203-210.

Sher-Kaul, S., B. Oertli, E. Castella \& J. Lachavanne, 1995. Relationship between biomass and surface area of six submerged aquatic plant species. Aquatic Botany 51: 147-154.

Shumway, C. A., H. A. Hofmann \& A. P. Dobberfuhl, 2007. Quantifying habitat complexity in aquatic ecosystems. Freshwater Biology 52: 1065-1076.

Smart, R. M. \& G. O. Dick, 1999. Propagation and establishment of aquatic plants: a handbook for ecosystem restoration projects. Technical Report A-99-4, U.S. Army Engineer Waterways Experiment Station, Vicksburg, MS

Stinson, C.S. A. \& V. K. Brown, 1983. Seasonal changes in the architecture of natural plant communities and its relevance to insect herbivores.Oecologia 56: 70-78.

Stoner, A. W. \& F. G. I. Lewis, 1985. The influence of quantitative and qualitative aspects of habitat complexity in tropical seagrass meadows. Journal of Experimental Marine Biology and Ecology 94: 40-49.

Stouffer, D. B. \& J. Bascompte, 2011. Compartmentalization increases food-web persistence. Proceedings of the National Academy of Sciences 108: 3648-3652.

Taniguchi, H. \& M. Tokeshi, 2004. Effects of habitat complexity on benthic assemblages in a variable environment. Freshwater Biology 49: 1164-1178.

Taniguchi, H., S. Nakano \& M. Tokeshi, 2003. Influences of habitat complexity on the diversity and abundance of epiphytic invertebrates on plants. Freshwater Biology 48: 718-728.

Tews, J., U. Brose, V. Grimm, K. Tielbörger, M. C. Wichmann, M. Schwager \& F. Jeltsch, 2004. Animal species diversity driven by habitat heterogeneity/diversity: the importance of keystone structures. Journal of Biogeography 31: 79-92.

Thébault, E. \& C. Fontaine, 2010. Stability of ecological communities and the architecture of mutualistic and trophic networks. Science 329: 853-856.

Thomaz, S. M., E. D. Dibble, L. R. Evangelista, J. Higuti \& L. M. Bini, 2008. Influence of aquatic macrophyte habitat complexity on invertebrate abundance and richness in tropical lagoons. Freshwater Biology 53: 358-367.

Tokeshi, M. \& S. Arakaki, 2011. Habitat complexity in aquatic systems: fractals and beyond. Hydrobiologia. doi: 10.1007/s10750-011-0832-z.

Tylanakis, J. M., T. Tscharntke \& O. T. Lewis, 2007. Habitat modification alters the structure of tropical host-parasitoid food webs. Nature 445: 202-205. 
van Nes, E. H. \& M. Scheffer, 2005. Implications of spatial heterogeneity for catastrophic regime shifts in ecosystems. Ecology 86: 1797-1807.

van Oevelen, D., G. Duineveld, M. Lavaleye, F. Mienis, K. Soetaert \& C. H. R. Heipa, 2009. The cold-water coral community as a hot spot for carbon cycling on continental margins: a food-web analysis from Rockall Bank (northeast Atlantic). Limnology and Oceanography 54: 1829-1844.

Walters, L. J. \& D. S. Wethey, 1996. Settlement and early postsettlement survival of sessile marine invertebrates on topographically complex surfaces: the importance of refuge dimensions and adult morphology. Marine Ecology Progress Series 137: 161-171.

Warfe, D. M. \& L. A. Barmuta, 2004. Habitat structural complexity mediates the foraging success of multiple predator species. Oecologia 141: 171-178.

Warfe, D. M. \& L. A. Barmuta, 2006. Habitat structural complexity mediates food web dynamics in a freshwater macrophyte community. Oecologia 150: 141-154.
Warfe, D. M., L. A. Barmuta \& S. Wotherspoon, 2008. Quantifying habitat structure: surface convolution and living space for species in complex environments. Oikos 117: 1764-1773.

Wedding, L. M., A. M. Friedlander, M. McGranaghan, R. S. Yost \& M. E. Monaco, 2008. Using bathymetric lidar to define nearshore benthic habitat complexity: implications for management of reef fish assemblages in Hawaii. Remote Sensing of Environment 112: 4159-4165.

Wilding, T. A., C. A. Rose \& M. J. Downie, 2007. A novel approach to measuring subtidal habitat complexity. Journal of Experimental Marine Biology and Ecology 353: 279-286.

Willis, S. C., K. O. Winemiller \& H. Lopez-Fernandez, 2005. Habitat structural complexity and morphological diversity of fish assemblages in a Neotropical floodplain river. Oecologia 142: 284-295.

Zavada, D. G. \& J. C. Brock, 2009. A multiscale analysis of coral reef topographic complexity using Lidar-derived bathymetry. Journal of Coastal Research 53: 6-15. 